Article

\title{
Sentinel-2 for Mapping Iron Absorption Feature Parameters
}

\section{Harald van der Werff * and Freek van der Meer}

Faculty of Geo-information Science and Earth Observation, University of Twente, Drienerlolaan 5, 7522 NB, Enschede, The Netherlands; E-Mail: f.d.vandermeer@utwente.nl

* Author to whom correspondence should be addressed; E-Mail: harald.vanderwerff@utwente.nl; Tel.: +31-53-4874-535; Fax: +31-53-4874-336.

Academic Editors: James Jin-King Liu, Lenio Soares Galvao, Nicolas Baghdadi and Prasad S. Thenkabail

Received: 12 August 2015 / Accepted: 9 September 2015 / Published: 25 September 2015

\begin{abstract}
Iron is an indicator for soil fertility and the usability of an area for cultivating crops. Remote sensing is the only suitable tool for surveying large areas at a high temporal and spatial interval, yet a relative high spectral resolution is needed for mapping iron contents with reflectance data. Sentinel-2 has several bands that cover the $0.9 \mu \mathrm{m}$ iron absorption feature, while space-borne sensors traditionally used for geologic remote sensing, like ASTER and Landsat, had only one band in this feature. In this paper, we introduce a curve-fitting technique for Sentinel-2 that approximates the iron absorption feature at a hyperspectral resolution. We test our technique on library spectra of different iron bearing minerals and we apply it to a Sentinel-2 image synthesized from an airborne hyperspectral dataset. Our method finds the wavelength position of maximum absorption and absolute absorption depth for minerals Beryl, Bronzite, Goethite, Jarosite and Hematite. Sentinel-2 offers information on the $0.9 \mu \mathrm{m}$ absorption feature that until now was reserved for hyperspectral instruments. Being a satellite mission, this information comes at a lower spatial resolution than airborne hyperspectral data, but with a large spatial coverage and frequent revisit time.
\end{abstract}

Keywords: Sentinel-2; Hymap; iron absorption feature; mineralogy; soils; hyperspectral; Cabo de Gata 


\section{Introduction}

The European Commission (EC) and European Space Agency (ESA) have established the European Earth Observation programme Copernicus, previously known as the Global Monitoring for Environment and Security (GMES), to address issues related to monitoring of the environment. The space component consists of satellite missions labelled Sentinel 1 up to 5 [1]. These missions are to provide routine observations for operational Copernicus services and data continuity for current operational satellite systems [2]. Sentinel-2 carries a super-spectral sensor with 13 bands in the Visible and Near InfraRed (VNIR) and ShortWave InfraRed (SWIR) wavelength region. The spatial resolution of these bands differs between $10 \mathrm{~m}, 20 \mathrm{~m}$ or $60 \mathrm{~m}$ (Table 1). The platform orbits the Earth in a sun-synchronous $786 \mathrm{~km}$ high orbit that allows a coverage between -56 and +84 degrees latitude with a $290 \mathrm{~km}$ swath width. The revisit time at the equator is 10 days for a single satellite, which will drop to 5 days when both planned satellites will fly simultaneously [2].

Table 1. Spectral position $(\lambda$, in $\mathrm{nm})$ and bandwidth $(\Delta \lambda$, in $\mathrm{nm})$, spatial resolution $(\mathrm{R}$, in $\mathrm{m})$, heritage and purpose of Sentinel-2 bands, according to the Copernicus derived user requirements. Modified after [2,3] and used with permission from [4].

\begin{tabular}{|c|c|c|c|c|c|}
\hline \# & $\lambda$ & $\Delta \lambda$ & $\mathbf{R}$ & Heritage & Purpose \\
\hline 1 & 443 & 20 & 60 & ALI, LS8, MODIS & Atmospheric correction (aerosol scattering) \\
\hline 2 & 490 & 65 & 10 & LS7, LS8, MERIS & $\begin{array}{l}\text { Vegetation senescing, carotenoid, browning and soil background; } \\
\text { atmospheric correction (aerosol scattering) }\end{array}$ \\
\hline 3 & 560 & 35 & 10 & LS7, LS8, MERIS, SPOT5 & Green peak, sensitive to total chlorophyll in vegetation \\
\hline 4 & 665 & 30 & 10 & LS7, LS8, MERIS & Max. chlorophyll absorption \\
\hline 5 & 705 & 15 & 20 & MERIS & $\begin{array}{l}\text { Red edge position; consolidation of atmospheric corrections/ } \\
\text { fluorescence baseline. }\end{array}$ \\
\hline 6 & 740 & 15 & 20 & MERIS & Red edge position; atmospheric correction; retrieval of aerosol load \\
\hline 7 & 783 & 20 & 20 & ALI, MERIS & Leaf area index; edge of the NIR plateau \\
\hline 8 & 842 & 115 & 10 & LS7, LS8, SPOT5 & Leaf area index \\
\hline $8 \mathrm{a}$ & 865 & 20 & 20 & ALI, LS8, MERIS & $\begin{array}{l}\text { NIR plateau, sensitive to total chlorophyll, biomass, Leaf area index } \\
\text { and protein; water vapour absorption reference; retrieval of aerosol } \\
\text { load and type }\end{array}$ \\
\hline 9 & 945 & 20 & 60 & MERIS, MODIS & Atmospheric correction (water vapour absorption) \\
\hline 10 & 1375 & 30 & 60 & LS8, MODIS & Atmospheric correction (detection of thin cirrus) \\
\hline 11 & 1610 & 90 & 20 & LS7, LS8, SPOT5 & $\begin{array}{l}\text { Sensitive to lignin, starch and forest above ground biomass; } \\
\text { snow/ice/cloud separation }\end{array}$ \\
\hline 12 & 2190 & 180 & 20 & LS7, LS8 & $\begin{array}{l}\text { Assessment of Mediterranean vegetation conditions; distinction of } \\
\text { clay soils for monitoring of soil erosion; distinction between live } \\
\text { biomass, dead biomass and soil, e.g., for burn scars mapping }\end{array}$ \\
\hline
\end{tabular}

MODIS $=$ Moderate Resolution Imaging Spectrometer, ALI $=$ Advanced Land Imager, LS7 $=$ Landsat ETM + , LS8 $=$ Landsat 8, MERIS $=$ MEdium Resolution Imaging Spectrometer, SPOT $=$ Satellite Pour l'Observation de la Terre.

The potential of Sentinel-2 has been explored for a variety of land surface parameter estimations: Leaf Area Index (LAI) [5-7]; chlorophyll and nitrogen [8]; biophysical parameters [9,10]; and red edge position [8,11]. A study on Normalized Difference Vegetation Index (NDVI) time series continuity was done for operational sensors, which included National Oceanic and Atmospheric 
Administration (NOAA) Advanced Very High Resolution Radiometer (AVHRR) 9, Landsat Enhanced Thematic Mapper (ETM+), Satellite Pour l'Observation de la Terre (SPOT) Vegetation, Advanced Land Imager (ALI), Moderate Resolution Imaging Spectroradiometer (MODIS) and MEdium Resolution Imaging Spectrometer (MERIS) [12]. Outside the realm of physical variables were evaluations for water quality studies [13] and mapping of coral reefs [14].

The potential for geological applications was evaluated by van der Meer et al. [4]. The Copernicus derived user requirements [3] predominantly aim at environmental monitoring and do not specify geological remote sensing other than clay minerals, as shown by the Sentinel-2 band purposes in Table 1.

Geologists increasingly study phenomena that are dynamic in space and time (e.g., active geothermal systems, oil and gas seeps, coastal environments), and they require time series of inter-calibrated and cross-calibrated data products rather than only archived data $[4,15,16]$. Geologic remote sensing is based on spectral analysis of minerals and rocks, initially conducted by Hunt and Salisbury [17-19]. Goetz and Rowan [20] used Landsat Multispectral Scanner (MSS) to derive iron oxide maps for the first time. Landsat Thematic Mapper (TM) allowed the use of band ratios for separating argillic from non-argillic materials (using bands 5/7) and for mapping ferric and ferrous oxides (using bands 3/1). The Advanced Spaceborne Thermal Emission and Reflection Radiometer (ASTER) [16,21,22] has become the "work horse" for satellite mapping of surface mineralogy since its launch in 1999.

The six SWIR bands of ASTER in particular allow mapping of surface mineralogy due to their relatively narrow spectral resolution [23], and has lead to a series of band ratios that serve as proxies for mineral assemblages or individual mineral groups [24]. The recently launched Worldview-3 sensor has 8 SWIR bands, of which four were taken from the ASTER design [25]. Sentinel-2 lacks such narrow bands in the SWIR bands (Figure 1), and van der Meer et al. [4] then also concluded that proxies obtained with Sentinel-2 were the same as what could be obtained with Landsat, albeit on a slightly higher spatial resolution.

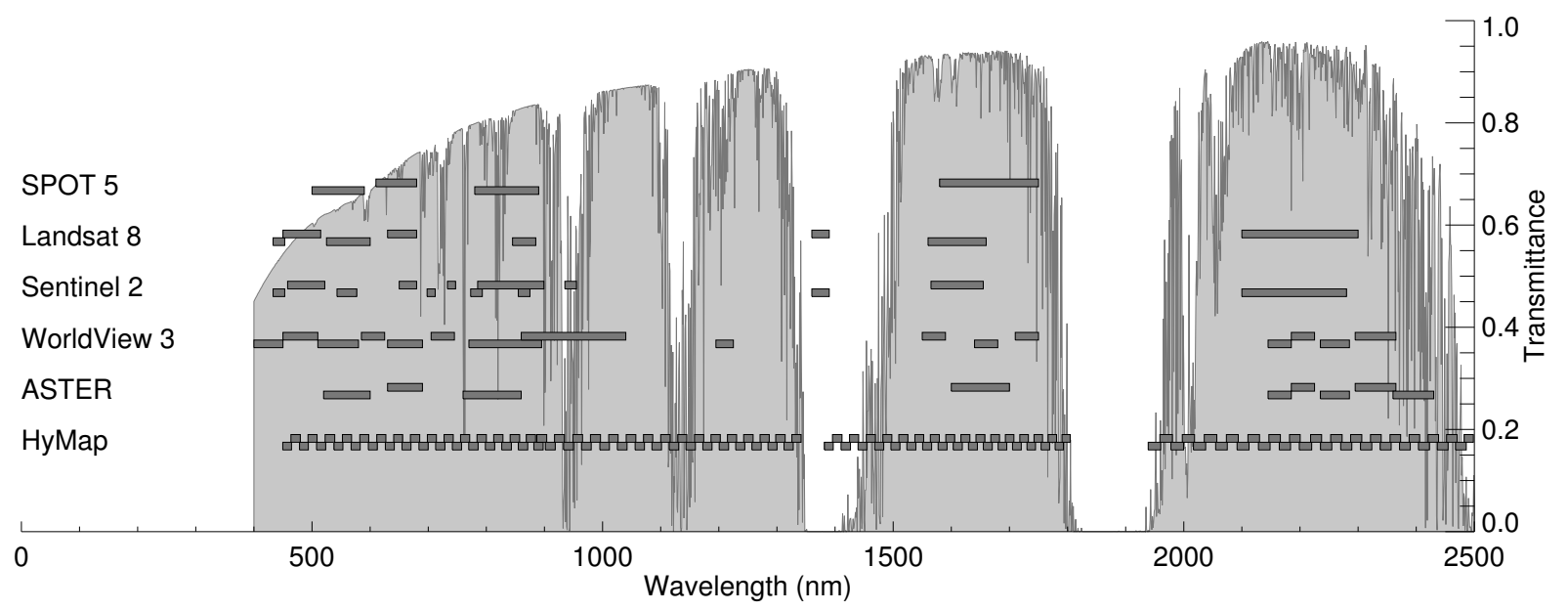

Figure 1. The bands of the Sentinel-2 sensor, in comparison to SPOT 5, Landsat 8, Worldview-2 \& 3, ASTER \& Hymap. Atmospheric transmittance is plotted in a grey shade against the Y-axis. Used with permission from [4]. 
The super-spectral design of Sentinel-2 however does provide several relatively narrow bands in the VNIR that cover the iron absorption feature at $0.9 \mu \mathrm{m}$ (Figure 2): While ASTER and Landsat only have 1 band in the $0.9 \mu \mathrm{m}$ wavelength region, Sentinel-2 has several.

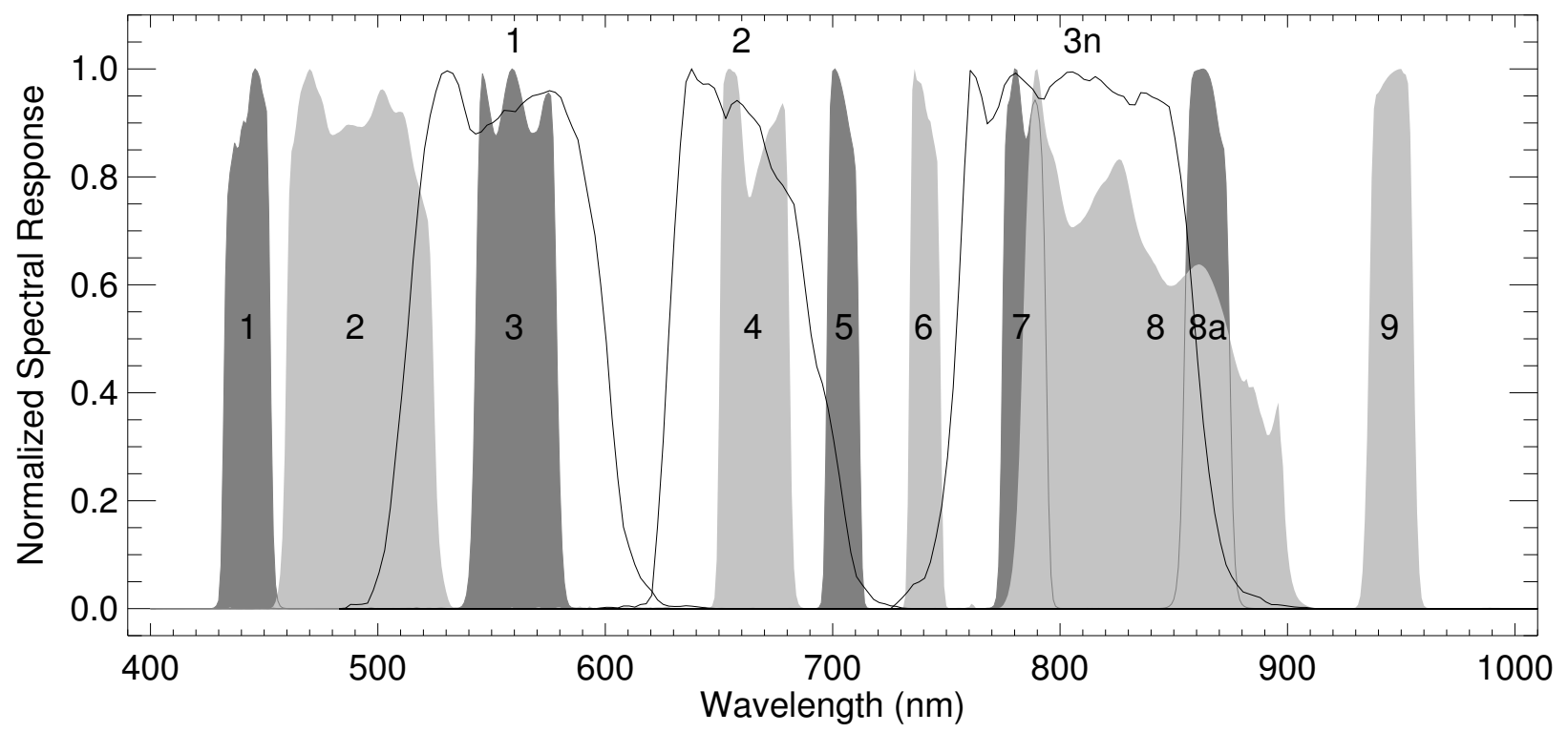

Figure 2. Spectral response functions of Sentinel-2 (shaded areas) and Aster (solid lines) in the VNIR wavelength range. Used and modified with permission from [4].

Iron is fourth most common mineral found in the earth crust [26]. Although it may not be as important for soil fertility as e.g., phosphorus, nitrogen and organic matter, its absence would be detrimental to plant growth. Iron is thus an indicator for soil fertility and the usability of an area for cultivation of crops [27]. A relative high spectral resolution is needed for mapping iron contents with reflectance data [26], and remote sensing is the only suitable tool for surveying large areas at a high temporal and spatial interval.

Landsat TM has been used for a quantitatively determining iron contents [28], but the low spectral resolution made different absorption features are not separable. Mielke et al. [29] evaluated several current and next-generation satellite sensors for mapping iron feature depth. They were able to use multiple bands of Sentinel-2 in a complex band-ratio approach and found next-generation sensors such as Sentinel-2 to be better equipped for measuring iron feature depth than the current multi-spectral sensors. The obtained product was the relative depth of the iron feature, indicating a bulk presence of iron, which essentially could also be provided by the ASTER band ratios of Cudahy and Hewson [24].

The aim of our paper is to try and go beyond mapping with band ratios, and to apply image processing methods that potentially could be repeatable and quantifiable. We intend to use Sentinel-2 VNIR bands to reconstruct the absorption feature at a hyperspectral resolution for mapping of iron bearing minerals with parameters that describe the shape of the $0.9 \mu \mathrm{m}$ absorption feature: the wavelength position of maximum absorption together with the feature depth.

We first introduce our method to reconstruct the shape of the iron absorption feature from Sentinel-2 bands. We test the method on several library spectra of different iron bearing minerals and subsequently 
apply it, in the absence of real data, to a synthetic Sentinel-2 image. This synthetic image was resampled from an airborne hyperspectral dataset to study the effect of spectral and spatial degradation in relation to the hyperspectral dataset, and to conclude whether our novel use of upcoming Sentinel-2 data is feasible or not.

\section{Method and Study Area}

Charting mineral spectral absorption by determining absorption feature parameters such as wavelength position, depth and width assumes nearly continuous (contiguous) spectral data [30]. Imaging spectrometers acquire data in many but discrete spectral bands, and multi-spectral sensors have even wider gaps in wavelength coverage. To model the shape of an absorption feature from spectrally lower resolution bands, interpolation techniques are often used, e.g., [30-32]. In our approach, we fit a polynomial function through the reflectance-at-surface values of Sentinel-2 bands.

\subsection{The Parabola Fitting Technique}

The width of Sentinel-2 band 8 is $115 \mathrm{~nm}$ at half maximum (Table 1; Figure 2), which proved to be too wide for usage in fitting a curve through the iron absorption feature. Bands 6, 7, 8a and 9 are relatively narrow compared to the iron absorption feature and should thus in principle be usable. Band 9 $(945 \mathrm{~nm}$ ) has a pixel size of $60 \mathrm{~m}$ and is purposely positioned in an atmospheric absorption feature for aid in atmospheric correction. Nevertheless, it can be used for curve fitting, provided that the dataset is corrected with an atmospheric model prior to application. A consequence, however, is that the spatial resolution of the resulting maps is also at $60 \mathrm{~m}$.

As only a few bands are available in Sentinel-2 for fitting polynomials, we decided to use a curve that requires only 3 values to determine the fit of a curve: a 2 nd degree polynomial, or parabola. We applied a parabola fitting technique for all wavelength positions $x$ between $0.75 \mu \mathrm{m}$ and $0.90 \mu \mathrm{m}$ at a $1 \mathrm{~nm}$ wavelength interval, to approximate the absorption feature at a hyperspectral resolution:

$$
w_{x}=a x^{2}+b x+c
$$

where

$w_{x} \quad$ the interpolated reflectance value at position $\mathrm{x}$;

$x \quad$ wavelength position in $\mathrm{nm}$;

$a, b, c$ coefficients of the parabola function.

\subsection{Optimizing With a Spectral Library}

The first dataset tested with the parabola fitting technique was a spectral library. The dataset was made by resampling spectra of the United States Geological Survey (USGS) mineral spectral library [33], which covers a contiguous $0.2-3.0 \mu \mathrm{m}$ wavelength range. Resampling was done in IDL-ENVI software (http://www.exelisvis.com) using spectral response functions of Sentinel-2 that were kindly provided by the European Space Agency. 
From the resampled library, the minerals Beryl, Bronzite, Pigeonite, Olivine, Spessartine and Staurolite from the so-called Hunt \& Salisbury collection were chosen for testing, following Figure 2 in Hunt [19]. To continue citing Hunt [19], the spectra of these "6 minerals with ferrous ions" display a shift of the "wavelength of maximum absorption" from shorter to longer wavelengths due to "ferrous ions in different crystal fields or in different sites".

Additional testing was done on iron mineralogy spectra that are associated with monitoring of mine tailings. The minerals Bronzite, Diopside, Goethite, Hematite and Jarosite were chosen, inspired by Mielke et al. [29] who tested band ratios with synthetic Sentinel-2 data, amongst other sensors. In addition, a Grass vegetation spectrum was used to show the behaviour of our technique on vegetation.

These datasets were used to find the optimal settings of the model by evaluating the fit of the parabolas to the original spectra, and to determine the wavelength range in which the model is valid. It was derived by trial and error that the selection of bands that covered the widest wavelength interval (bands $6,8 \mathrm{a}$ and 9) provided an optimal fit of the parabola to the original library spectra. Making use of band 9 at $945 \mathrm{~nm}$ center wavelength was found to be essential in order to fit parabolas. As band 9 has a spatial resolution of $60 \times 60 \mathrm{~m}$, the processing results would consequently have a $60 \mathrm{~m}$ spatial resolution as well.

\subsection{Application to Synthetic Sentinel-2 Imagery}

After determining with the spectral library which bands to use to construct the parabolas, we applied the parabola fitting technique to image data. The image dataset was created by spectrally and spatially resampling a Hymap airborne hyperspectral image to the band definitions of Sentinel-2 (Figure 3). This synthetic image was also used in van der Meer et al. [4], and their paper includes an analysis of the spectral and spatial resampling used.

The Hymap data were acquired on 18 May 2004 by the German Aerospace Center (DLR), and processed to reflectance-at-surface values at a nominal $5 \mathrm{~m}$ spatial sampling interval. The processing included geometric correction with PARGE software [34] using a $5 \mathrm{~m}$ interval digital elevation model, followed by an atmospheric correction with ATCOR 4 software [35].

The Hymap data were first spectrally convolved to the lower resolutions of the Sentinel- 2 bands. The spectral coverage of Hymap is nearly continuous in the VNIR and SWIR wavelength regions, with gaps in the $1.4 \mu \mathrm{m}$ and $1.9 \mu \mathrm{m}$ water absorption bands. The wavelength range, nominal band width and sampling interval of the 4 detectors are:

VIS $0.45-0.89 \mu \mathrm{m}, 15-16 \mathrm{~nm}, 15 \mathrm{~nm}$;

NIR $0.89-1.35 \mu \mathrm{m}, 15-16 \mathrm{~nm}, 15 \mathrm{~nm}$;

SWIR1 $1.40-1.80 \mu \mathrm{m}, 15-16 \mathrm{~nm}, 13 \mathrm{~nm}$;

SWIR2 $1.95-2.48 \mu \mathrm{m}, 18-20 \mathrm{~nm}, 17 \mathrm{~nm}$.

After spectral resampling, the data were spatially resampled from the approximately $5 \mathrm{~m}$ resolution of the Hymap data to the $10 \mathrm{~m}, 20 \mathrm{~m}$ and $60 \mathrm{~m}$ spatial resolutions of Sentinel-2. In the absence of a point spread function that describes the response of the Sentinel-2 sensor to the sampled area, we 
used pixel aggregation (neighbourhood averaging), following Kruse and Perry [25] in their simulation of Worldview-3 data.
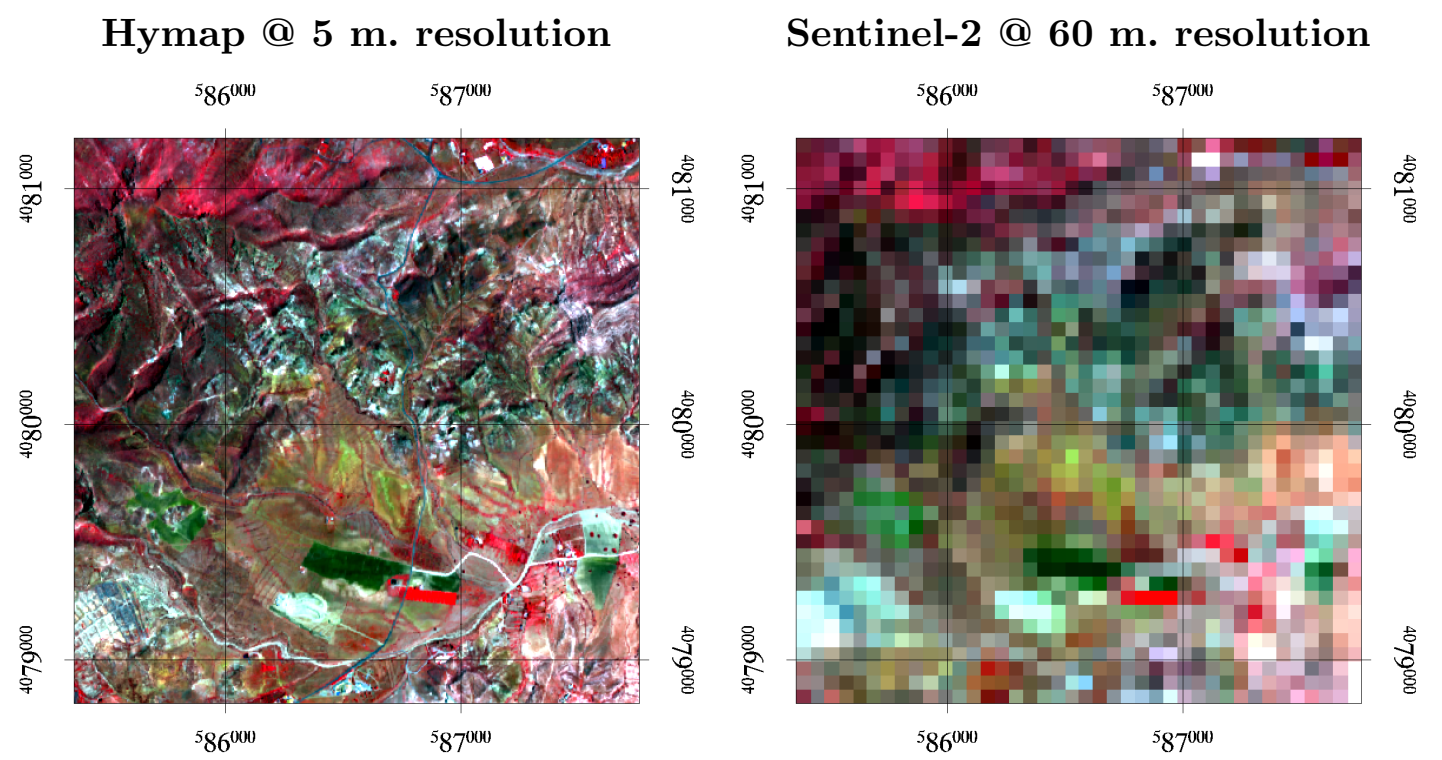

Figure 3. The Hymap imagery at its original $5 \times 5 \mathrm{~m}$ spatial resolution (left) and the dataset resampled to Sentinel-2 spectral bands at a $60 \times 60 \mathrm{~m}$ spatial resolution (right). Both datasets are shown in a near-infrared false color composite, with Hymap bands R: 29 (861 nm), G: $15(650 \mathrm{~nm})$ and $\mathrm{B}: 8(543 \mathrm{~nm})$. These figures depict vegetated areas in bright red tones and bare reddish soil and rock outcrops in dark green tones. Soils covered by sparse vegetation have a green-brownish tone in this color composite. Band 9 of Sentinel-2 is essential for fitting of parabolas through the spectra, and its $60 \times 60 \mathrm{~m}$ pixel consequently became the spatial resolution for all Sentinel-2 products derived in this study. The location of the area covered by this scene is shown in Figure 4.

We compared the results obtained with the parabola fitting technique on the synthetic Sentinel-2 image to those obtained with the Hymap dataset. As the aim was to study the effect of spectral and spatial degradation separately, four datasets were created and analysed:

1. an original image with 22 Hymap bands at the original $5 \mathrm{~m}$ spatial resolution;

2. a synthetic image with 22 Hymap bands resampled to $60 \mathrm{~m}$ spatial resolution;

3. a synthetic image with 4 Sentinel-2 bands at the original $5 \mathrm{~m}$ spatial resolution;

4. a synthetic image with 4 Sentinel-2 bands resampled to $60 \mathrm{~m}$ spatial resolution.

\subsection{Mapping Absorption Feature Parameters}

The four image datasets were first masked for vegetation, as a vegetation cover would partially or completely mask any underlying soil and disturb the shape of the iron absorption feature [36]. The NDVI was calculated for each of the four images separately, and pixels with values outside the 
range 0.0-0.3 DN were masked and removed from the datasets (The NDVI images and resulting masks can be found in the supplemental materials).

The masked images were exposed to the parabola fitting technique, using bands $6,8 \mathrm{a}$ and 9 for the Sentinel-2 resolution spectra and bands 15, 28 and 35 for the Hymap resolution spectra. Pixels with negative parabolas or with positive parabolas that had the point of maximum absorption outside the 0.7-1.0 $\mu \mathrm{m}$ wavelength range were masked. In the remaining pixels, the wavelength of maximum absorption was determined, as well as the depth of the feature relative to the convex hull, following [31]. Within the $0.7-1.0 \mu \mathrm{m}$ wavelength range, the interpolated wavelength position of the minimum $w_{\min }$ of the resulting parabola was calculated:

$$
w_{\text {min }}=-\frac{b}{2 a}
$$

where

$w_{\text {min }}$ the interpolated wavelength position at minimum reflectance;

$a, b \quad$ coefficients of the parabola function.

as well as the depth $d_{\min }$ of that absorption feature:

$$
d_{\min }=1-f\left(w_{\min }\right)
$$

where

$d_{\min }$ the interpolated depth of absorption feature.

The obtained absorption feature parameters, wavelength of maximum absorption and feature depth, were compared with scatter-plots between the 4 image datasets.

\subsection{Study Area}

We use a Hymap airborne hyperspectral dataset for simulation of Sentinel-2 image data. The Hymap data was acquired over an hydrothermal alteration area located in the Sierra del Cabo de Gata [37] in the south-eastern part of Spain (Figure 4). The Cabo de Gata volcanic field consists of calc-alkaline volcanic rocks (andesites and rhyolites) of late Tertiary age. These rocks have been extensively altered to form an assemblage of high to low temperature grade metamorphic minerals, such as Silica, Alunite, Kaolinite, Montmorillonite and Chlorite. The geology of the area is described in Arribas et al. [38], while several remote sensing studies were conducted at this site as well [4,39-42].

A spatial subset of $600 \times 600$ Hymap pixels was used as the experimental dataset for this study. This subset covers an area of approximately $6 \mathrm{~km}^{2}$, and its location is indicated in Figure 4 by the box labelled "Area 1". In the final stage of this study, a larger subset of $1750 \times 1750$ Hymap pixels was used to mimic a regional scale mapping. This subset is part of a mosaic of 4 Hymap flight-lines and covers an approximate area of $50 \mathrm{~km}^{2}$, and its location is indicated in Figure 4 by the box labelled "Area 2". 


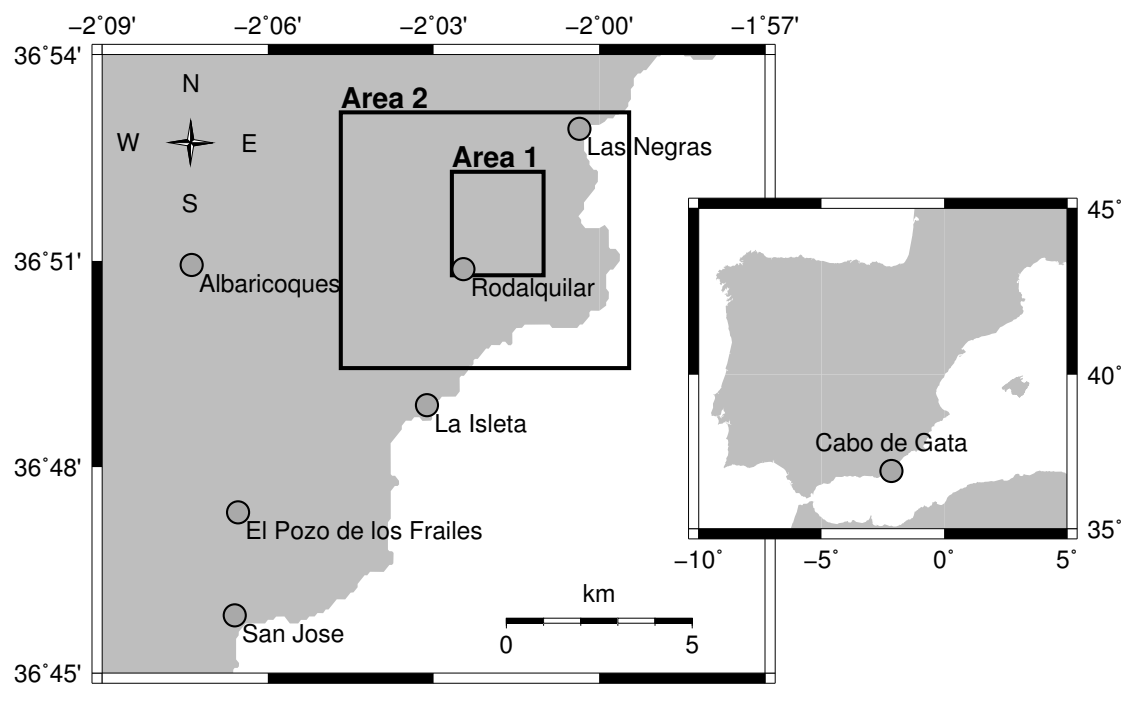

Figure 4. Location of the study area in South-east Spain, near the town of Rodalquilar within the Sierra del Cabo de Gata. The image coverage of our study is labelled "Area 1" for Figure 3 and the first two figures of Section 3.2, and "Area 2" for the last figure of Section 3.2.

\section{Results}

\subsection{Validating Against Library Spectra}

We first fitted parabolas to library spectra that were resampled to the spectral band definitions of Sentinel-2. We chose six mineral spectra after [19], that display a shift of the absorption feature due to "ferrous ions in different crystal fields or in different sites". Figure 5 shows the results of fitting parabolas through bands 6, 8a and 9 (Other band combinations and polynomials were also tested, but these test revealed only lesser fits to the original library spectra. These results are available in the supplemental materials of this paper). From the figure can be seen that parabolas could be constructed for all 6 minerals of the Hunt \& Salisbury collection (left column), but that only the minerals Beryl and Bronzite have (1) a positive parabola with (2) a wavelength position of maximum absorption within the $0.7-1.0 \mu \mathrm{m}$ range. Olivine also has a positive parabola, but the maximum absorption comes at a wavelength longer than $1.0 \mu \mathrm{m}$. The minerals Pigeonite, Spessartine and Staurolite have a negative parabola, indicating that the fit could not be representative of an absorption feature. For the spectra of vegetation and the 5 minerals associated with acid mine drainage (right column), positive parabolas with a wavelength position of maximum absorption within the $0.7-1.0 \mu \mathrm{m}$ range could be constructed for Bronzite, Goethite, Hematite and Jarosite. The mineral Diopside has a negative parabola, as has the Grass vegetation spectrum.

\subsection{Application to Imagery}

The comparison between the four image datasets, consisting of Hymap at $5 \mathrm{~m}$ and $60 \mathrm{~m}$ spatial resolution and Sentinel-2 at $5 \mathrm{~m}$ and $60 \mathrm{~m}$ spatial resolution, is in Figures 6 and 7 . These figures show 
the degradation of the spectral resolution (horizontally, in images labelled c, $\mathrm{f}$ and i) and the degradation of the spatial resolution (vertically, in images labelled $g, h$ and i) in scatter-plots, while the 4 images top-left (labelled a, b, d and e) illustrate resulting differences in spatial patterns.
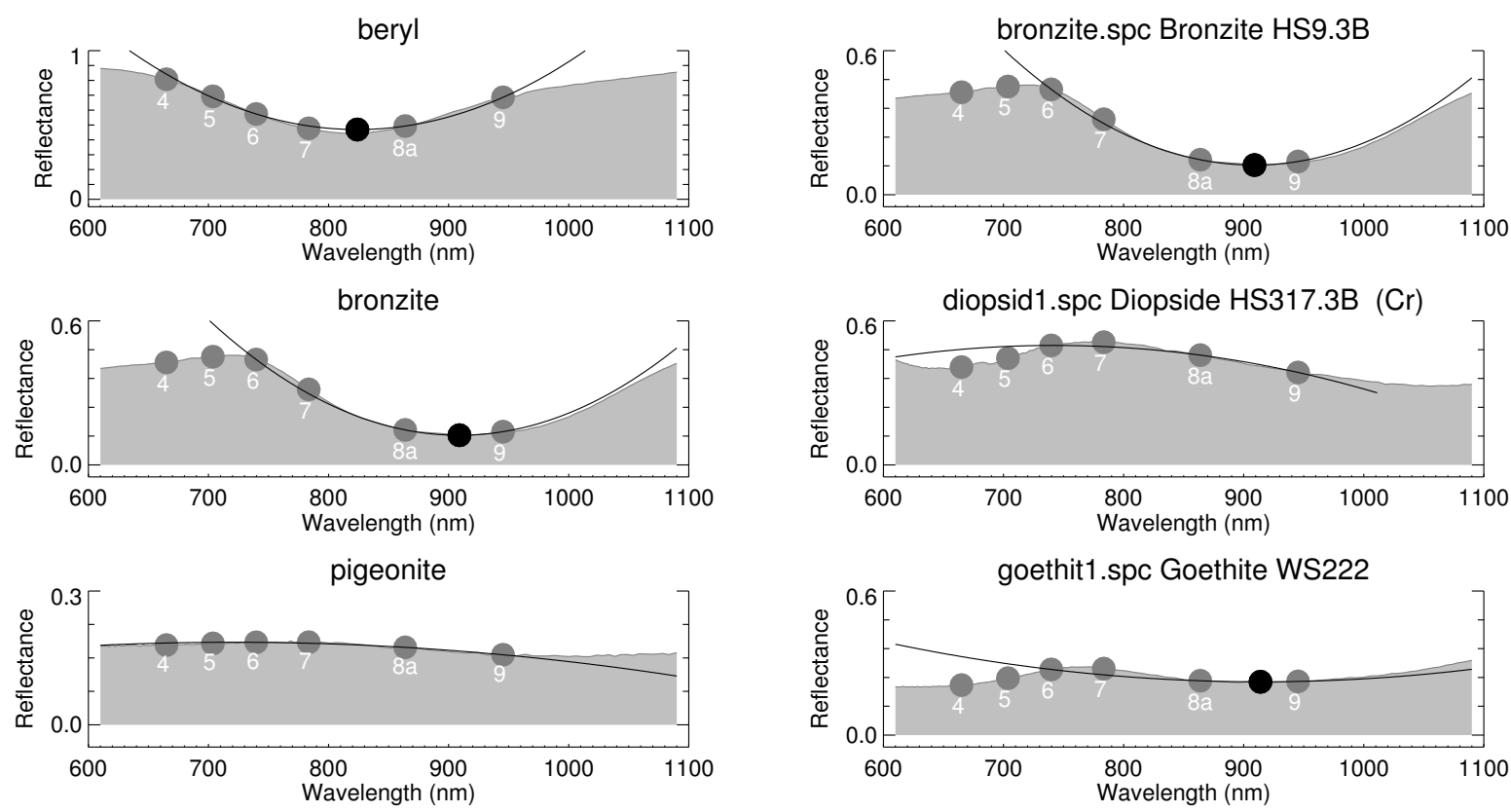

goethit1.spc Goethite WS222
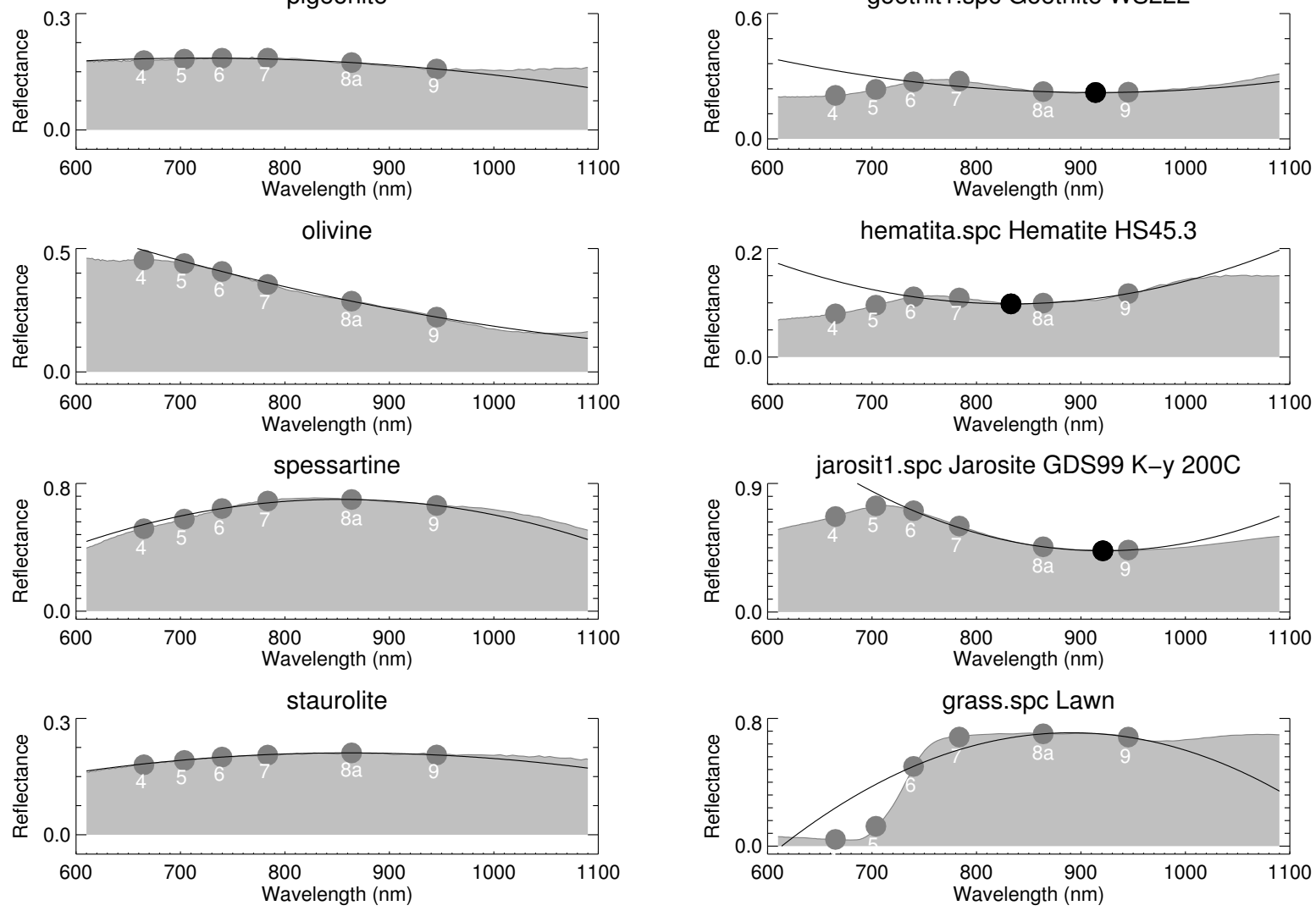

Figure 5. Left: Spectra of six minerals which contains ferrous ions, either in different crystal fields or in different sites, after Hunt [19]. Right: Spectra of iron mineralogy associated with mine tailings, selected following Mielke et al. [29], and a "Grass" vegetation spectrum. The figures show the USGS library spectra (light grey shaded areas), the sentinel bands (dark grey dots), the fitted parabola (black lines) and deduced wavelength of maximum absorption (black dots).

Figure 6 shows the results for wavelength position of maximum absorption. The scatter-plots $\mathrm{c}$ and $\mathrm{f}$ on the right-hand side the figure show a gain in the wavelength values when only spectral degradation 
is done. The scatter-plots $\mathrm{g}$ and $\mathrm{h}$ at the bottom of Figure 6 show the impact of degrading a $5 \mathrm{~m}$ spatial resolution to $60 \mathrm{~m}$. The bottom-right scatter-plot i contains the effect of both spectral and spatial degradation, and shows that the effect of lower spatial resolution is stronger than a spectral resolution change only. Still, the spatial patterns observed in all four images seem to remain consistent based on visual interpretation. Figure 7 shows the results for depth of the absorption feature. The trends in this image are similar to those observed in Figure 6, although the loss of information by spatial degradation is less pronounced in feature depth than in wavelength position.

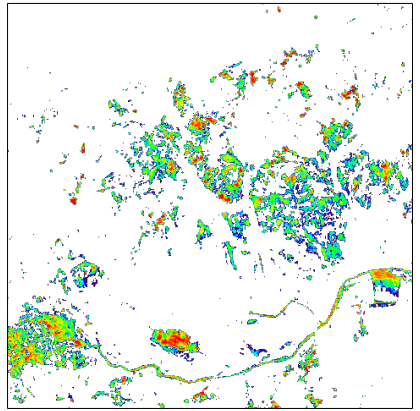

(a) Hymap $5 \times 5$ wavelength

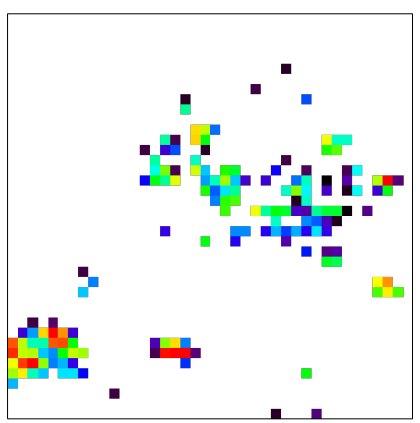

(d) Hymap $60 \times 60$ wavelength

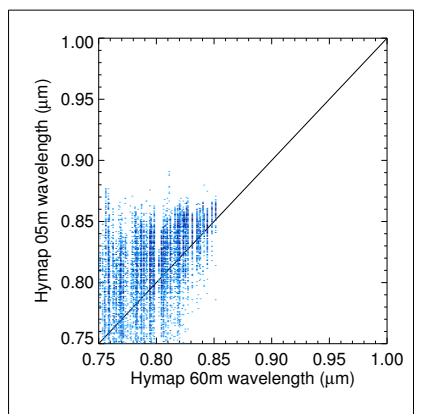

(g) Scatter a \& d (spatial)

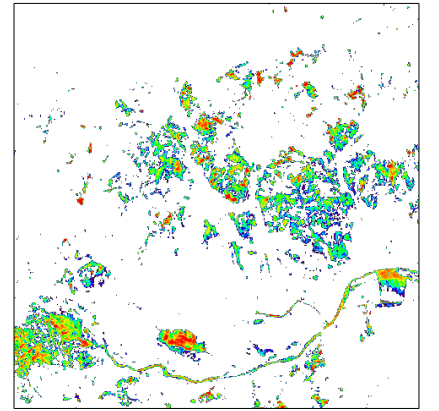

(b) Sentinel-2 $5 \times 5$ wavelength

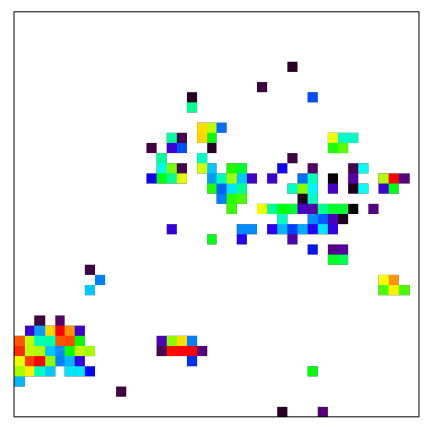

(e) Sentinel-2 $60 \times 60$ wavelength

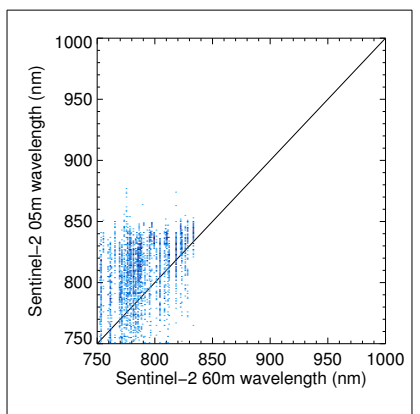

(h) Scatter b \& e (spatial)

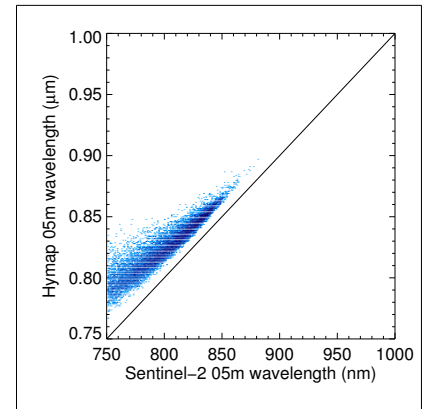

(c) Scatter a \& b (spectral)

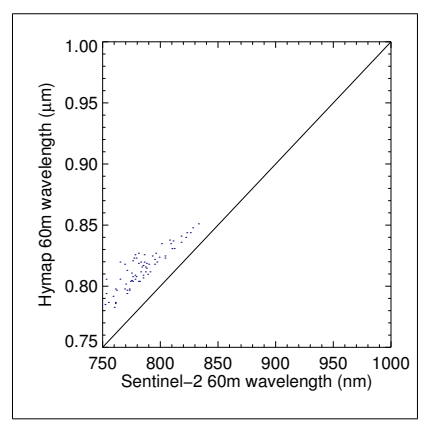

(f) Scatter d \& e (spectral)

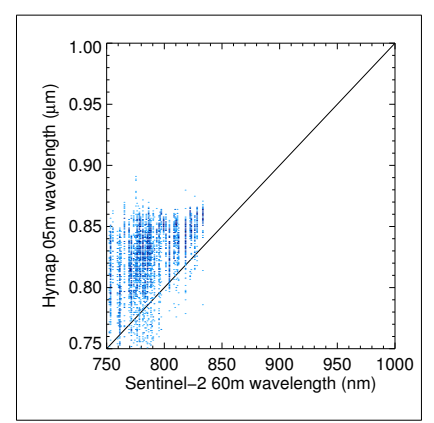

(i) Scatter a \& e (spec \& spat)

Figure 6. The wavelength position of maximum absorption found in the parabolas fitted through Sentinel-2 and Hymap bands. Images a, b, d and e show Hymap and Sentinel-2 results at 5 and $60 \mathrm{~m}$ spatial resolution, in a $2 \%-98 \%$ linear stretch with colorramp low high. The area covered by these 4 images is shown in Figure 4. The scatterplots in Figure $6 \mathbf{c}, \mathbf{f}-\mathbf{i}$ show the differences between the images with a colorramp low $1 \mathbf{m i g h}$ : Scatterplots $\mathrm{c}$ and $\mathrm{f}$ show the impact of spectral degradation only; scatterplots $\mathrm{g}$ and $\mathrm{h}$ show the impact of degrading the $5 \mathrm{~m}$ spatial resolution to $60 \mathrm{~m}$; and scatter-plot $\mathrm{i}$ shows the combined effect of spectral and spatial degradation. 


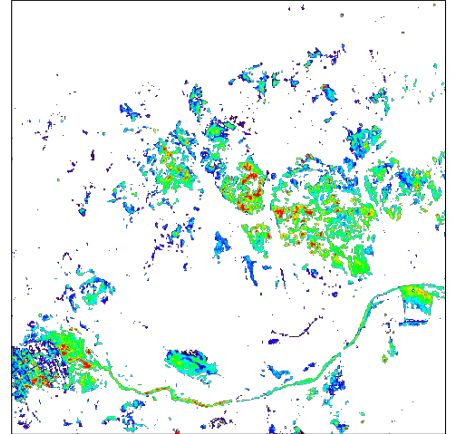

(a) Hymap $5 \times 5$ feature depth

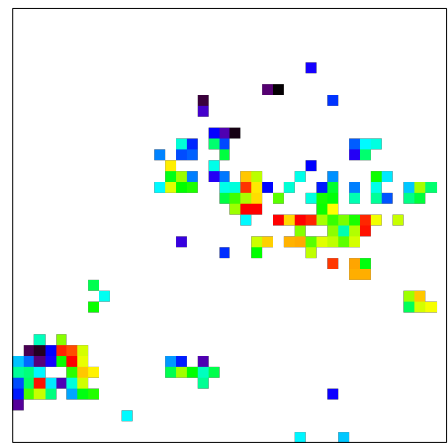

(d) Hymap $60 \times 60$ feature depth

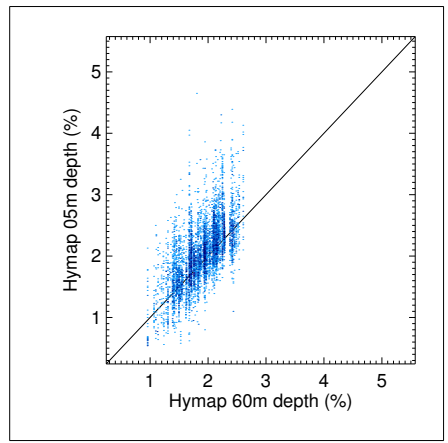

(g) Scatter a \& d (spatial)

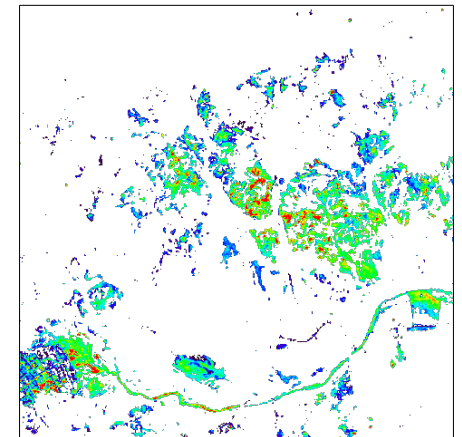

(b) Sentinel-2 $5 \times 5$ feature depth

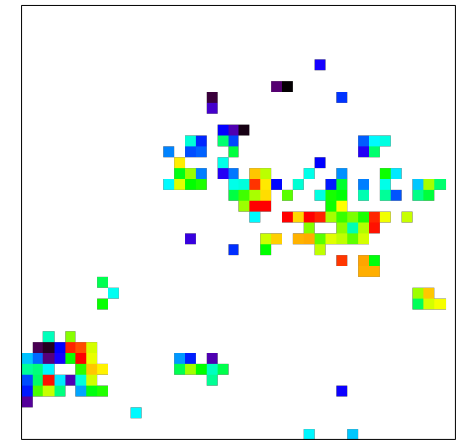

(e) Sentinel-2 $60 \times 60$ feature depth

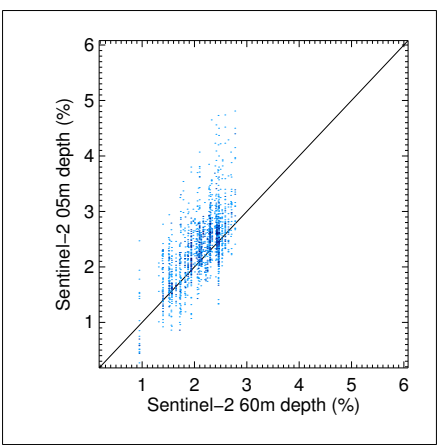

(h) Scatter b \& e (spatial)

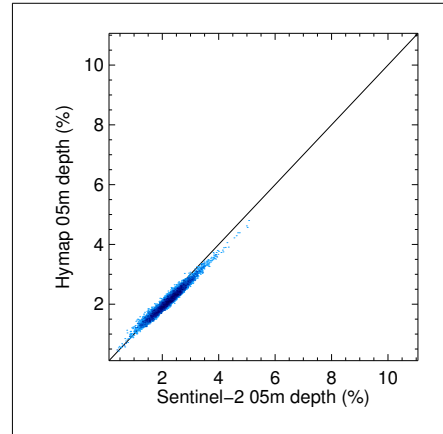

(c) Scatter a \& b (spectral)

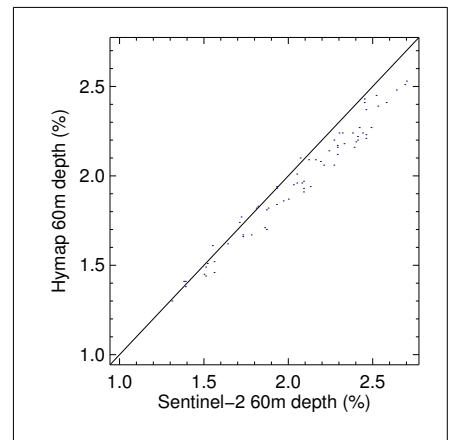

(f) Scatter d \& e (spectral)

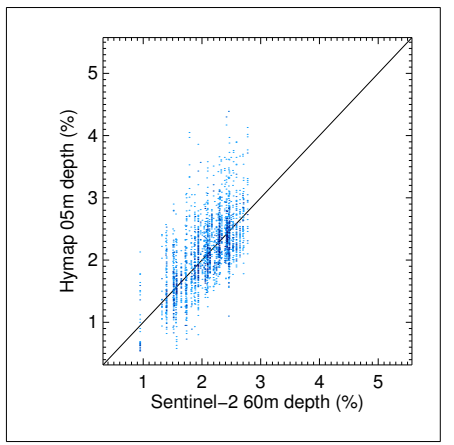

(i) Scatter a \& e (spec \& spat)

Figure 7. The depth of the absorption feature found in the parabolas fitted through Sentinel-2 and Hymap bands. Images $\mathbf{a}, \mathbf{b}, \mathbf{d}$ and $\mathbf{e}$ show Hymap and Sentinel-2 results at 5 and $60 \mathrm{~m}$ spatial resolution, in a 2\%-98\% linear stretch with colorramp low covered by these 4 images is shown in Figure 4 . The scatterplots in Figure $7 \mathbf{c}, \mathbf{f}-\mathbf{i}$ show the differences between the images with a colorramp low $1 \mathrm{migh}$ : Scatterplots c and f show the impact of spectral degradation only; scatterplots $g$ and $h$ show the impact of degrading the $5 \mathrm{~m}$ spatial resolution to $60 \mathrm{~m}$; and scatter-plot i shows the combined effect of spectral and spatial degradation.

Figure 8 shows the result of mapping the iron absorption feature over a $50 \mathrm{~km}^{2}$ area, which includes the image subset used in Figures 6 and 7. Although there is a significant difference in spectral information obtained at $5 \mathrm{~m}$ resolution or at $60 \mathrm{~m}$ resolution, especially the maps for wavelength position of the maximum absorption (labelled a and b) show an encouraging amount of consistency. 


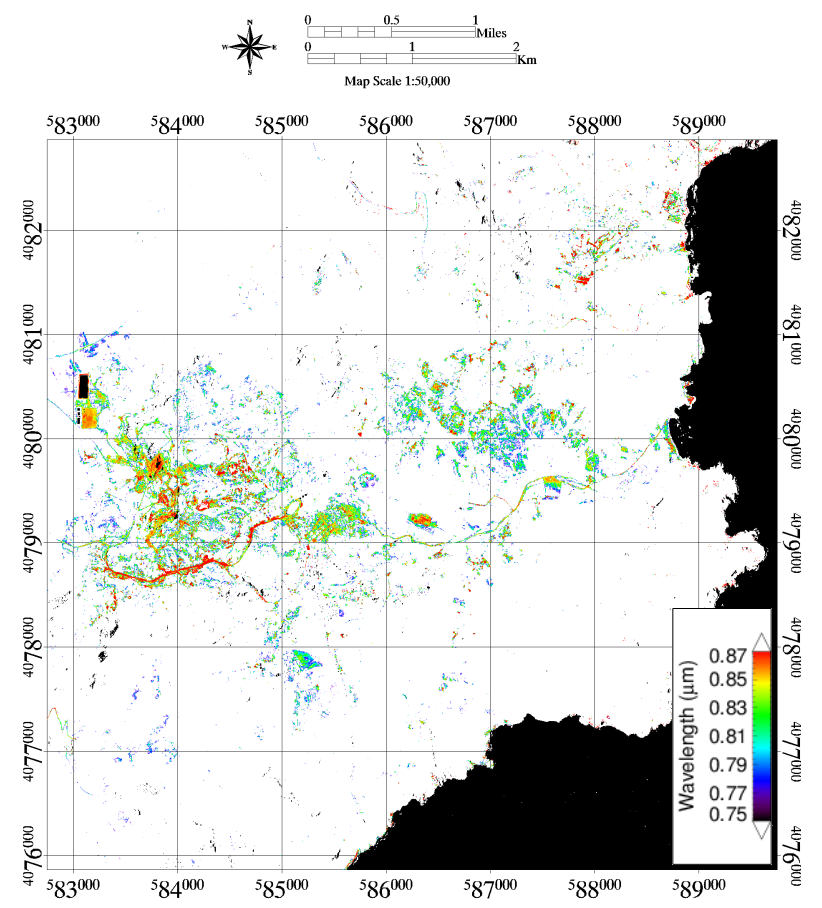

(a) Hymap wavelength position

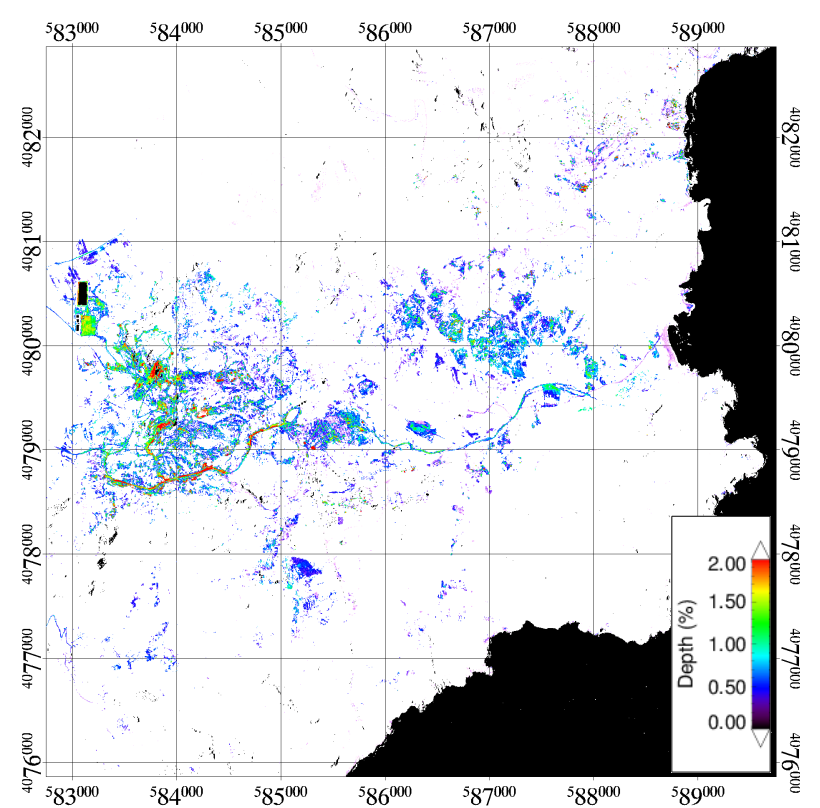

(c) Hymap feature depth

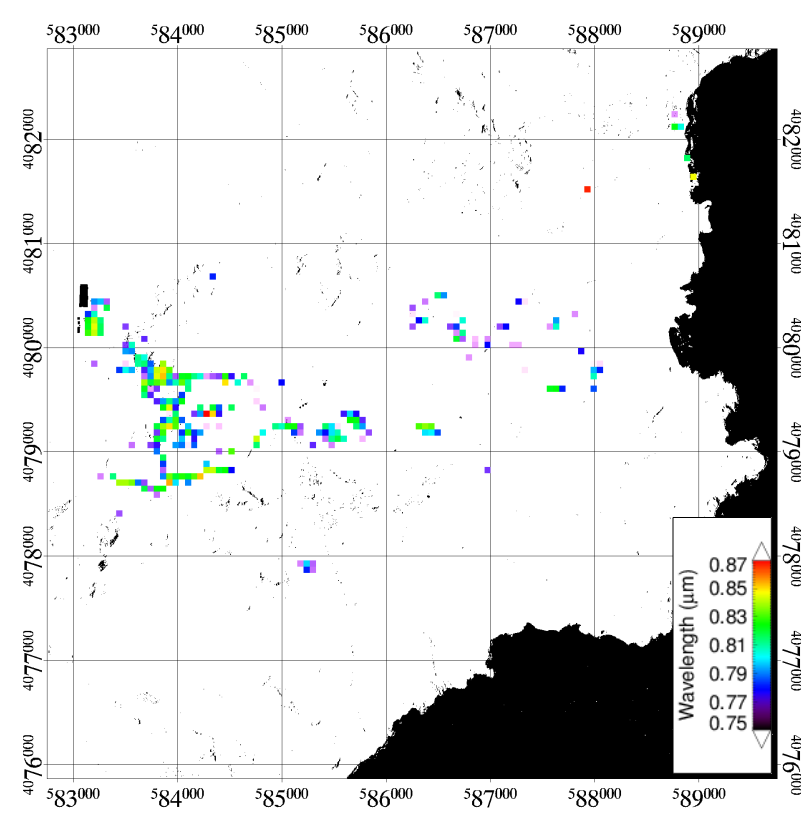

(b) Sentinel-2 wavelength position

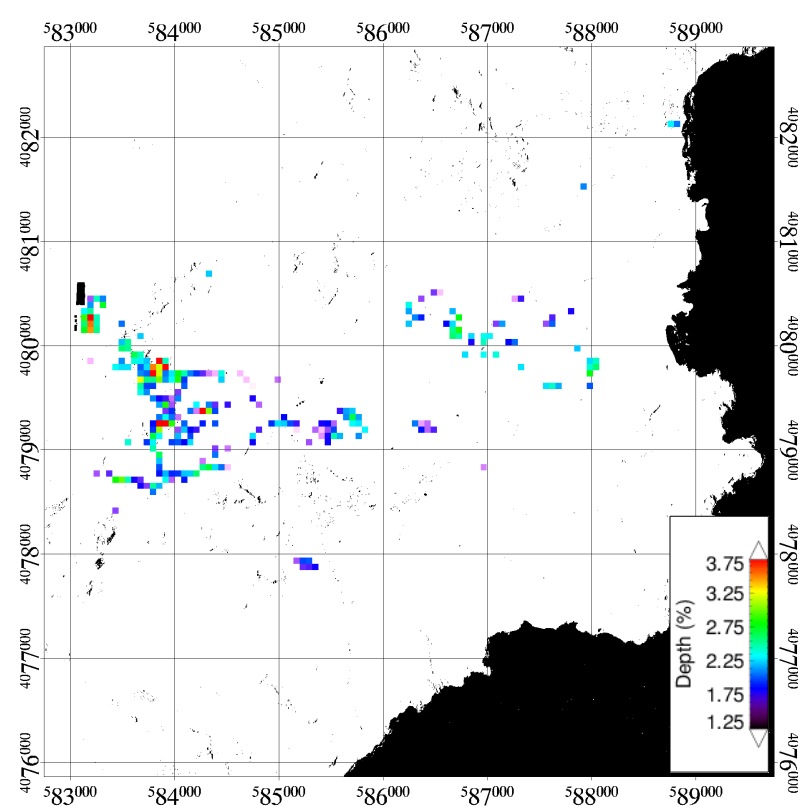

(d) Sentinel-2 feature depth

Figure 8. Mapping the $0.9 \mu \mathrm{m}$ absorption feature over the Cabo de Gata region. Shown are the absorption feature parameters "wavelength of maximum absorption" (a,b) and the "absorption feature depth" (c,d), obtained with Hymap hyperspectral imagery (a,c) and simulated Sentinel-2 imagery $(\mathbf{b}, \mathbf{d})$. The location of the area covered by these images is shown in Figure 4. 


\section{Discussion}

Figure 5 shows that positive parabolas can be constructed for the minerals Beryl, Bronzite, Goethite, Hematite and Jarosite, which all have a wavelength position of maximum absorption within the 0.7-0.9 $\mu \mathrm{m}$ wavelength range. For the other minerals, either the fitted parabola is positive but the wavelength position of maximum absorption is beyond $0.9 \mu \mathrm{m}$ wavelength, or the fitted parabola is negative and therefore lacking a minimum value.

Comparisons of the absorption feature parameters between synthetic Sentinel-2 data and Hymap data, in Figures 6 and 7, show that spectral degradation is not affecting the absorption feature parameters as much as spatial degradation does. In fact, these two figures prove that our technique is capable of producing similar results as hyperspectral data, when only spectral degradation would be the difference. The pronounced effect of spatial degradation, however, leads to conclude that the information obtained from a $60 \mathrm{~m}$ pixel is simply different than what can be obtained from a high spatial resolution dataset. At such a relatively low resolution for land applications, vegetation is more likely to be present in the sensor's instantaneous-field-of-view, and spatial linear mixing is likely to decrease the contrast between different mineralogy. While green vegetation dominates a pixel, this pixel can be masked using NDVI. Spectral unmixing of dry vegetation from a pixel would require the use of e.g., a cellulose absorption index (CAI) [43], which can only be derived from (relatively narrow) hyperspectral SWIR bands. Sentinel-2 band $12(2190 \mathrm{~nm})$ however is aimed, amongst other purposes, at distinction between live and dead biomass (Table 1), and could possibly be used to improve the applicability of our method.

A spectral approximation of absorption feature information can be done as long as the lower resolution bands are placed at wavelength positions appropriate for the absorption feature studied. In the case of Sentinel-2 and the iron absorption feature, this holds for the minerals Beryl, Bronzite, Goethite, Hematite and Jarosite. Our technique could possibly be improved by involving the red and green wavelength range to fit other functions, as to avoid the use of band 9 with its $60 \mathrm{~m}$ spatial resolution in future research. For the minerals Goethite and Hematite the fit seems not as good as for the other minerals; this could possibly be improved by introducing separate band sets per target mineral for defining parabolas. Still, the results presented in this paper already indicate that our curve fitting technique can approximate the absorption features of several minerals that are important in monitoring of soils or mine waste.

The study presented in this paper is based on simulated imagery, and our synthetic image has some differences with the future actual data. First, the field-of-view of the Sentinel-2 bands can be expected to differ from what we obtained with a spatial degradation by pixel aggregation. The actual point spread function of the Sentinel-2 sensor will sample a slightly larger field-of-view than what we used by the exact given pixel size in following [25]. Secondly, the lossy compression of data used on-board Sentinel-2 was not taken into account. However, any possible impact on data quality is likely to be at noise level when studying natural scenes, and we expect that there will not be a major impact on the results of our study. A last difference that may arise is that the atmospheric correction in our synthetic dataset was based on the information of many bands provided by the Hymap sensor. An atmospheric correction of Sentinel-2 relies on the information of only a few bands, which include band 9 that is used in our mapping technique. An assessment as to whether our technique could actually provide 
operational products over larger areas would require testing on real Sentinel-2 imagery in combination with a verification against ground cover data.

ESA's Sentinel-2 mission will eventually cover the Earth on a 10-60 m spatial resolution at a 5 days revisit time. The Sentinel-2 VNIR bands were originally designed to map vegetation parameters (Table 1). Figure 8 shows that its design also allows mapping of iron feature parameters, here obtained over a $50 \mathrm{~km}^{2}$ area in South-east Spain. Sentinel-2 thus offers information on soil composition that until now was reserved for hyperspectral instruments. The imagery has a lower spatial resolution than airborne hyperspectral sensors, but will therefore have a large spatial coverage and a frequent revisit time for a fraction of the costs for end-users.

\section{Conclusions}

In this paper, we introduced a technique to model the shape of the iron absorption feature with Sentinel-2. The super-spectral Sentinel-2 sensor has multiple bands in the 0.7-0.9 $\mu \mathrm{m}$ wavelength region, where space-borne missions traditionally used for geologic remote sensing, such as ASTER and Landsat, only provided a single band. By using selected VNIR bands as input for a parabola curve-fitting approach, the spectral absorption feature at $0.9 \mu \mathrm{m}$ can be approximated for specific minerals. This includes several minerals that are important in monitoring of soils and mine waste, such as Bronzite, Goethite, Jarosite and Hematite. While previously only the relative iron feature depth could be mapped with multi-spectral sensors, by using band ratio techniques, our technique offers the possibility to map the wavelength position of maximum absorption and to derive an absolute depth of the feature. Sentinel-2 thus offers information on the $0.9 \mu \mathrm{m}$ absorption feature that until now was reserved for hyperspectral instruments. Being a satellite mission, this information comes at a lower spatial resolution than that of an airborne hyperspectral sensor, but it comes with a large spatial coverage and high revisit time.

A high revisit time will lead to a more frequent coverage of an area. This leads to alternative solutions in addressing the problem of spectral unmixing of soil and vegetation. For starters, there is a better chance of being able to use images acquired in winter. Of a more philosophical thought is that the spatial mixing that occurs in a relatively large pixel can be analysed within a time-series rather than by linear spatial unmixing. Soil moisture content, for example, changes on a daily base, and vegetation cover changes within seasons. Both changes occur at a much shorter time span than one would expect from changes in soil composition, particularly mineralogy. This opens a new realm of remote sensing image analysis for soil composition, namely sub-pixel image analysis by studying the change in time rather than in space. Combined with mapping iron contents, not only feature depth but also the wavelength position, Sentinel-2 will bring us information on iron oxides that previous multi-spectral missions could not.

\section{Acknowledgements}

The authors are grateful to Michael Berger and Ferran Gascon Roca of the European Space Agency for providing the spectral response functions of Sentinel-2. Steven M. de Jong of Utrecht University is acknowledged for fruitful discussions, Mila I. Luleva is acknowledged for reviewing an earlier version of this paper. 


\section{Author Contributions}

Harald van der Werff is the principal author of this manuscript and responsible for the conception and design of this research, as well as data collection, analysis and interpretation. Freek van der Meer contributed to the conception of evaluating Sentinel-2 for geological applications, as well as discussion and review of this manuscript.

\section{Conflicts of Interest}

The authors declare no conflict of interest.

\section{References}

1. Berger, M.; Moreno, J.; Johannessen, J.A.; Levelt, P.F.; Hanssen, R.F. ESA's sentinel missions in support of Earth system science. Remote Sens. Environ. 2012, 120, 84-90.

2. Drusch,M.; Del Bello, U.; Carlier, S.; Colin, O.; Fernandez, V.; Gascon, F.; Hoersch, B.; Isola, C.; Laberinti, P.; Martimort, P.; et al. Sentinel-2: ESA's optical high-resolution mission for GMES operational services. Remote Sens. Environ. 2012, 120, 25-36.

3. European Space Agency. GMES Sentinel-2 Mission Requirements Document; Technical Report Issue 2 Revision 1; European Space Agency, March, 2010. Available online: http://esamultimedia.esa.int/docs/GMES/Sentinel-2_MRD.pdf (accessed on 22 September 2015).

4. van der Meer, F.D.; van der Werff, H.M.A.; van Ruitenbeek, F.J.A. Potential of ESA's Sentinel-2 for geological applications. Remote Sens. Environ. 2014, 148, 124-133.

5. Atzberger, C.; Richter, K. Spatially constrained inversion of radiative transfer models for improved LAI mapping from future Sentinel-2 imagery. Remote Sens. Environ. 2012, 120, 208-218.

6. Richter, K.; Atzberger, C.; Vuolo, F.; Weihs, P.; D’Urso, G. Experimental assessment of the Sentinel-2 band setting for RTM-based LAI retrieval of sugar beet and maize. Can. J. Remote Sens. 2009, 35, 230-247.

7. Richter, K.; Hank, T.B.; Vuolo, F.; Mauser, W.; D’Urso, G. Optimal exploitation of the Sentinel-2 spectral capabilities for crop leaf area index mapping. Remote Sens. 2012, 4, 561-582.

8. Clevers, J.G.P.W.; Gitelson, A.A. Remote estimation of crop and grass chlorophyll and nitrogen content using red-edge bands on Sentinel-2 and -3. Int. J. Appl. Earth Obs. Geoinfor. 2013, 23, 344-351.

9. Frampton, W.J.; Dash, J.; Watmough, G.; Milton, E.J. Evaluating the capabilities of Sentinel-2 for quantitative estimation of biophysical variables in vegetation. ISPRS J. Photogramm. Remote Sens. 2013, 82, 83-92.

10. Verrelst, J.; Munoz, J.; Alonso, L.; Delegido, J.; Rivera, J.P.; Camps-Valls, G.; Moreno, J. Machine learning regression algorithms for biophysical parameter retrieval: Opportunities for Sentinel-2 and -3. Remote Sens. Environ. 2012, 118, 127-139. 
11. Delegido, J.; Verrelst, J.; Meza, C.M.; Rivera, J.P.; Alonso, L.; Moreno, J. A red-edge spectral index for remote sensing estimation of green LAI over agroecosystems. Eur. J. Agron. 2013, $46,42-52$.

12. D'Odorico, P.; Gonsamo, A.; Damm, A.; Schaepman, M.E. Experimental evaluation of Sentinel-2 spectral response functions for NDVI time-series continuity. IEEE Trans. Geosci. Remote Sens. 2013, 51, 1336-1348.

13. Salama, M.S.; Radwan, M.; van der Velde, R. A hydro-optical model for deriving water quality variables from satellite images (HydroSat): A case study of the Nile River demonstrating the future Sentinel-2 capabilities. Phys. Chem. Earth 2012, 50-52, 224-232.

14. Hedley, J.; Roelfsema, C.; Koetz, B.; Phinn, S. Capability of the Sentinel 2 mission for tropical coral reef mapping and coral bleaching detection. Remote Sens. Environ. 2012, 120, 145-155.

15. van der Meer, F.D.; van der Werff, H.M.A.; van Ruitenbeek, F.J.A.; Hecker, C.A.; Bakker, W.H.; Noomen, M.F.; van der Meijde, M.; Carranza, E.J.M.; de Smeth, J.B.; Woldai, T. Multi- and hyperspectral geologic remote sensing: A review. Int. J. Appl. Earth Obs. 2012, 14, 112-128.

16. Abrams, M. The advanced spaceborne thermal emission and reflection radiometer (ASTER): Data products for the high spatial resolution imager on NASA's Terra platform. Int. J. Remote Sens. 2000, 21, 847-859.

17. Cooper, B.L.; Salisbury, J.W.; Killen, R.M.; Potter, A.E. Midinfrared spectral features of rocks and their powders. J. Geophys. Res.-Planets 2002, 107, 1-17.

18. Salisbury, J.W.; Walter, L.S.; Vergo, N. Availability of a library of infrared (2.1-25.0 $\mu \mathrm{m})$ mineral spectra. Am. Mineral. 1989, 74, 938-939.

19. Hunt, G. Spectral signatures of particulate minerals in the visible and near-infrared. Geophysics 1977, 42, 501-513.

20. Goetz, A.F.H.; Rowan, L.C. Geologic remote-sensing. Science 1981, 211, 781-791.

21. Yamaguchi, Y.; Kahle, A.B.; Tsu, H.; Kawakami, T.; Pniel, M. Overview of advanced spaceborne thermal emission and reflection radiometer (ASTER). IEEE Trans. Geosci. Remote Sens. 1998, $36,1062-1071$.

22. Abrams, M.; Hook, S.J. Simulated ASTER data for geologic studies. IEEE Trans. Geosci. Remote Sens. 1995, 33, 692-699.

23. Mars, J.C.; Rowan, L.C. Spectral assessment of new ASTER SWIR surface reflectance data products for spectroscopic mapping of rocks and minerals. Remote Sens. Environ. 2010, 114, 2011-2025.

24. Cudahy, T.; Hewson, R. ASTER geological case histories: Porphyry-skarn-epithermal, iron oxide $\mathrm{Cu}-\mathrm{Au}$ and Broken Hill Pb-Zn-Ag. In Procedings of 2002 General Meeting of the Geological Remote Sensing Group: ASTER Unveiled, Burlington House, London, UK, 5-7 December 2002.

25. Kruse, F.A.; Perry, S.L. Mineral mapping using simulated Worldview-3 short-wave-infrared imagery. Remote Sens. 2013, 5, 2688-2703.

26. Ben-Dor, E.; Irons, J.; Epema, G. Soil reflectance. In Remote Sensing for the Earth Sciences: Manual of Remote Sensing; Rencz, A., Ed.; John Wiley \& Sons Inc.: New York, NY, USA, 1999; pp. 111-188. 
27. Bartholomeus, H.; Epema, G.; Schaepman, M. Determining iron content in Mediterranean soils in partly vegetated areas, using spectral reflectance and imaging spectroscopy. Int. J. Appl. Earth Obs. 2007, 9, 192-203.

28. Andrews Deller, M. Facies discrimination in laterites using Landsat Thematic Mapper, ASTER and ALI data-Examples from Eritrea and Arabia. Int. J. Remote Sens. 2006, 27, 2389-2409.

29. Mielke, C.; Boesche, N.; Rogass, C.; Kaufmann, H.; Gauert, C.; de Wit, M. Spaceborne mine waste mineralogy monitoring in South Africa, applications for modern push-broom missions: Hyperion/OLI and EnMAP/Sentinel-2. Remote Sens. 2014, 6, 6790-6816.

30. van der Meer, F.D. Analysis of spectral absorption features in hyperspectral imagery. Int. J. Appl. Earth Sci. 2004, 5, 55-68.

31. van Ruitenbeek, F.; Bakker, W.; van der Werff, H.; Zegers, T.; Oosthoek, J.; Omer, Z.; Marsh, S.; van der Meer, F. Mapping the wavelength position of deepest absorption features to explore mineral diversity in hyperspectral images. Planet. Space Sci. 2014, 101, 108-117.

32. Rodger, A.; Laukamp, C.; Haest, M.; Cudahy, T. A simple quadratic method of absorption feature wavelength estimation in continuum removed spectra. Remote Sen. Environ. 2012, 118, 273-283.

33. Clark, R.; Swayze, G.; Wise, R.; Livo, E.; Hoefen, T.; Kokaly, R.; Sutley, S. USGS Digital Spectral Library Splib06a; Digital Data Series 231; U.S. Geological Survey, 2007. Available online: http://speclab.cr.usgs.gov/spectral.lib06/ (accessed on 22 September 2015).

34. Schlapfer, D.; Richter, R. Geo-atmospheric processing of airborne imaging spectrometry data. Part 1: Parametric orthorectification. Int. J. Remote Sens. 2002, 23, 2609-2630.

35. Richter, R.; Schlapfer, D. Geo-atmospheric processing of airborne imaging spectrometry data. Part 2: Atmospheric/topographic correction. Int. J. Remote Sens. 2002, 23, 2631-2649.

36. Xu, Y.; Lin, Q.; Shao, Y.; Wang, L. Extraction mechanism of Alteration Zones using ASTER imagery. In Proceedings of International Geoscience and Remote Sensing Symposium (IGARSS), Anchorage, AK, USA, 20-24 September 2004.

37. Rytuba, J.J.; Arribas, A.; Cunningham, C.G.; McKee, E.H.; Podwysocki, M.H.; Smith, J.G.; Kelly, W.C. Mineralized and unmineralized calderas in Spain. Part II, evolution of the Rodalquilar caldera complex and associated gold-alunite deposits. Miner. Deposita 1990, 25, S29-S35.

38. Arribas, A.; Cunningham, C.; Rytuba, J.; Rye, R.; Kelly, W.; Podwysocki, M.; McKee, E.; Tosdal, R. Geology, geochronology, fluid inclusions, and isotope geochemistry of the Rodalquilar gold alunite deposit, Spain. Econ. Geol. Bull. Soc. Econ. Geol. 1995, 90, 795-822.

39. Bedini, E.; van der Meer, F.; van Ruitenbeek, F. Use of HyMap imaging spectrometer data to map mineralogy in the Rodalquilar caldera, southeast Spain. Int. J. Remote Sens. 2009, 30, 327-348.

40. Debba, P.; Carranza, E.J.M.; Stein, A.; van der Meer, F.D. Deriving optimal exploration target zones on mineral prospectivity maps. Math. Geosci. 2009, 41, 421-446.

41. van der Werff, H.; van Ruitenbeek, F.; van der Meijde, M.; van der Meer, F.; de Jong, S.; Kalubandara, S. Rotation-variant template matching for supervised hyperspectral boundary detection. IEEE Geosci. Remote Sens. Lett. 2007, 4, 70-74. 
42. Van der Meer, F. Indicator kriging applied to absorption band analysis in hyperspectral imagery: A case study from the Rodalquilar epithermal gold mining area, SE Spain. Int. J. Appl. Earth Obs. 2006, 8, 61-72.

43. Nagler, P.; Inoue, Y.; Glenn, E.; Russ, A.; Daughtry, C. Cellulose absorption index (CAI) to quantify mixed soil-plant litter scenes. Remote Sens. Environ. 2003, 87, 310-325.

(c) 2015 by the authors; licensee MDPI, Basel, Switzerland. This article is an open access article distributed under the terms and conditions of the Creative Commons Attribution license (http://creativecommons.org/licenses/by/4.0/). 